\title{
Results of postoperative anti-rotation on the intracapsular femoral neck fracture fixed with cannulated screws
}

bu-fang ren ( $\sim$ rbfdlh123@163.com )

department of orthopedics, the second hospital of shanxi medical university, 382 wuyi road, taiyuan shanxi province, china

quan-ping ma

department of orthopedics, the second of shanxi medical university

xin IV

department of orthopedics,the second hospital of shanxi medical university

yunsheng yin

department of othopedics,the second hospital of shanxi medical university

yaozhu gao

department of orthopedics ,the second hospital of shanxi medical university

\section{Technical advance}

Keywords: Femoral neck fracture, anti rotation, cannulated screws

Posted Date: June 16th, 2020

DOl: https://doi.org/10.21203/rs.3.rs-33671/v1

License: (c) (1) This work is licensed under a Creative Commons Attribution 4.0 International License.

Read Full License 
Results of postoperative anti-rotation on the intracapsular femoral neck fracture fixed with cannulated screws Bu-fang Ren, Quan-ping Ma, Xin Lv, Yun-sheng Yin, Yao-zhu Gao

\section{Abstract}

Background: To investigate effect of postoperative anti-rotation on the union of intracapsular displaced femoral neck fracture treated with three cannulated screws.

Methods: A retrospective analysis was performed on all the intracapsular femoral neck fractures treated in the department of orthopedics of the second Hospital of Shanxi Medical University from July 2015 to December 2018. Fractures of femoral neck were reduced and fixed with three cannulated screws. The patients who wore anti-rotation shoes in the affected side were kept at bed rest for 10-12 weeks after surgery. The results were analyzed.

Results: A total of 135 patients were included in the analysis. Six patients (4.4\%) were not united. There were 12 cases of avascular necrosis (9.3\%). No wound infections, screw breakages was found.

Conclusion: Anti-rotation after surgery can significantly reduce the rate of femoral neck fracture nonunion, but not significantly improve the femoral head necrosis

Keywords: Femoral neck fracture, anti-rotation, cannulated screws 
Femoral neck fracture is a common hip fracture, it can occur at any age. For displaced femoral neck fractures in the elderly, arthroplasty is preferred $^{1}$.Internal fixation was the primary treatment for the young patients with femoral neck fractures ${ }^{2}$. Despite advances in anatomic reduction and strong fixation, rates of nonunion and avascular necrosis are high and similar to those reported two decades ago ${ }^{3,4,5,6}$. Obviously not all factors contributing to the failure rate of the femoral neck fractures are related to the reduction and fixation. The treatment of femoral neck fractures should follow the AO principle, including anatomic reduction, strong fixation and appropriate postoperative rehabilitation. Orthopedic surgeons had payed more attention to reduction and fixation. The effect of postoperative rehabilitation on fracture healing was not clear.

Union of femoral neck fractures should be achieved through primary bone healing, which requires the absolute stability at the fracture site 7,8 . However, a clinical study has shown there was considerable rotational instability in the femoral neck fracture post fixation at four months follow-up ${ }^{9}$. Poor rotational stability is linked to high complications of a hip fracture. So, we adjust the postoperative rehabilitation program, instead of encouraging patients to mobilize with no restriction on range of motion of the hip after surgery in most 
literature. In our study the fracture of femoral neck was reduced and fixed with three parallel cannulated screws. After surgery, patient is kept at bed rest for 10-12 weeks and wore anti-rotation shoes in the fractured side. We hypothesis that would promote fracture healing.

\section{Methods}

This study was approved by the ethics committee of the local hospital. From July 2015 to December 2018, the clinical and imaging data of patients with intracapsular displaced femoral neck fracture fixed with cannulated screws, in the department of orthopedics of the second hospital of Shanxi medical university, were retrospectively analyzed. Patients with a pathologic fracture, an ipsilateral concomitant femoral, preexisting abnormalities of the femoral head or acetabular fracture were excluded. In addition, patients without complete clinical and radiographic data were excluded.

Preoperatively the affected limb was pulled. Warfarin sodium were subcutaneously injected until 12 hours before surgery. A closed reduction was attempted in every patient by The Whitman technique. Reduction attempts should not be forceful and should not be repeated more than two or three times. Once closed reduction was not satisfactory open reduction was admitted through a modified Smith-Petersen approach. Three partially threaded screws $(7.3 \mathrm{~mm})$ was 
be used after satisfactory reduction has been obtained(Fig1,2). Postoperatively, the patients wearing anti-rotational shoes in the affected side were kept at bed rest for 10-12 weeks(Fig3). Then partial weight bearing was recommended until fracture was united.

Follow-up clinical and radiologic analyses were performed at 6 weeks and 3, 6, 12 months after the operation. Non-union and avascular necrosis of femoral head were defined from $\mathrm{x}$-ray or magnetic resonance imagine.

\section{Statistical analysis}

This was carried out using SPSS 18.0 software (SPSS Inc., Chicago, Illinois) using chi-squared testing. The level of significance was set as a p-value $<0.05$

Results

A total of 135 patients received complete follow-up from July 2015 to December 2018. All patients were followed up for at least 24 months after the surgery. The reasons of injury included low-energy trauma (80 cases) and high-energy (55 cases). There were 61 females and 74 males, and 66 with injury on the left side and 69 on the right side. The average age of the total patient population was 50.1 years (range, 19-60 years). The time from fracture to surgery ranged from 2 to 16 days (average, 5.4 days). The closed reduction and fixation with cannulated screws were 
done in 128 patients. Seven patients required an open reduction and fixation with cannulated screws. The average time of union was 18.5 weeks (16 to 20 weeks5). Six patients (4.4\%) in whom there was no evidence of union at nine months after operation underwent total hip replacement. The average avascular necrosis was $8.9 \%$ (12 patients). No wound infections or screw breakages was found. There were no significant differences in age, sex, side of injury, and waiting time (time between initial injury and surgery) between the failure and heal group. There was significant difference in the quality of fracture reduction between the two groups $(p<0.001)($ Table 1$)$

Discussion

To reduce complications is a challenge to orthopedic surgeons. High rate of failure indicated that implant available for internal fixation of femoral neck fractures may not provide sufficient stability as we expected ${ }^{10,11,12}$. Some accessory methods should be used to supplement internal fixation. Postoperative anti-rotation was helpful to supplement internal fixation.

In our study the rate of nonunion was $4.4 \%$ and the figure compare favorably with other published results, with rates of nonunion of $11-40 \%{ }^{13,14,15,16}$. The result for a femoral head necrosis was $8.9 \%$ in the present study. In a meta-analysis, the author found the incidence of avascular necrosis of femoral head for those who sustained a displaced 
fracture was $20.6 \%{ }^{17}$. In another meta-analysis, the study demonstrated the total pooled incidence of avascular necrosis (AVN) was $14.3 \%{ }^{15}$.

There are two aspects of postoperative anti-rotation that can explain the results. First, according to the Whitman reduction technique, it involves applying traction to the abducted, extended, externally rotated hip with subsequent internal rotation. While patients were placed in the supine position, the lower extremities were in external rotation. Rotational force at fracture site easily resulted in a biomechanically unstable pattern, susceptible to the development of nonunion, osteonecrosis and implant failure ${ }^{18,19}$. Second, all movements of a ball-and-socket joint are rotational ${ }^{19}$ and the early movement of hip will result in rotational instability for the proximal fragment whether weight bearing or not ${ }^{20,21,22}$.So the postoperative anti-rotation eliminates these rotational stresses and provided absolutely stability for vascular regeneration,

Other factors also affected the results in this study. The average interval between the occurrence of fracture to surgery was 5.4 days in this study. In theory, early reduction and fixation is beneficial for reducing the initial vascular insult and revascularization in the setting of interrupted blood supply $23,24,25$. However the result of early fixation is contradictory. The effect of timing of internal fixation of femoral neck fracture needs to be further studied. 
In our study, all femoral neck fractures were fixed with three parallel cannulated screws. The application of cannulated screw fixation is simple and causes little damage to the soft tissue. There was no loss of reduction, implant cut-off, infection of surgical location in our study. In some case, fracture was united although the three screws were too close to each other, resulting in insufficient stability and inability to withstand rotational stresses.

Postoperative anti-rotation in bed can be frustrating. Compared with the disastrous complications, it is easy to be accepted for patients to be kept at bed rest for $10-12$ weeks. The patients with internal fixation were physiologically young. No complications were found when patients were kept at bed rest.

Our work had certain limitations: the study was retrospective. There was not control group. The follow up time was short. the function was not studied.

In conclusion, our study indicate postoperative anti-rotation is a simple and effective method which could provide suitable mechanical environments that facilitate direct bone formation and shorter healing times.

\section{Abbreviations}

Not applicable 


\section{Acknowledgements}

Not applicable

Authors' contributions

Not applicable

\section{Funding}

Not applicable

\section{Availability of data and materials}

The datasets used and analyzed during the current study are available from the corresponding author on reasonable request

\section{Ethics approval and consent to participate}

The study was approved by the Institutional Review Board/Ethics

Committee of the second Hospital of Shanxi Medical University

(reference number: SDEYEC-D-2019-012). The study was conducted according to the ethical principles stated in the Declaration of Helsinki

\section{Consent for publication}

The participants declare that they agree to publish the data described in the manuscript.

\section{Competing interests}

The authors declare that they have no competing interests.

\section{Author details}

Department of Orthopedics, The second Hospital of Shanxi Medical University, 382 Wuyi Road, Taiyuan, Shanxi province, 030001, China. 


\section{References}

1 Bhandari M, Devereaux PJ, Tornetta P $3^{\text {rd }}$,Swiontkowski MF, Berry DJ, Haidukewych G, Schemitsch EH, Hanson BP, Koval K, Leece P, Keel M, Petrisor B, Heetveld M, Guyatt GH. Operative management of displaced femoral neck fractures in elderly patients. An international survey. J Bone Joint Surg [Am] 2005;87-A:2122-2130.

2 Ly TV, Swiontkowski MF. Treatment of femoral neck fractures in young adults. J Bone Joint Surg [Am] 2008;90-A:2254-2266.

3 Rogmark C, Carlsson A, Johnell O, Sernbo I. A prospective randomised trial of internal fixation versus arthroplasty for displaced fractures of the neck of the femur. Functional outcome for 450 patients at two years. J Bone Joint Surg Br. 2002;84(2):183-188.

4 Partanen J, Saarenpää I, Heikkinen T, Wingstrand H, Thorngren KG, Jaloaara P. Functional outcome after displaced femoral neck fractures treated with osteosynthesis or hemiarthroplasty: a matched-pair study of 714 patients. Acta Orthop Scand. 2002;73(5):496-501.

5 Dedrick DK, Mackenzie JR, Burney RE. Complications of femoral neck fracture in young adults. J Trauma. 1986;26(10):932-937.

6 Karaeminogullari O, Demirors H, Atabek M,Tuncay C, Tandogan R, Ozalay M. Avascular necrosis and nonunion after osteosynthesis of femoral neck fractures: effect of fracture displacement and time to surgery. Adv Ther. 2004 Sep-Oct; 21(5):335-342. 
7 Samsami S, Saberi S, Sadighi S, Rouhi G. Comparison of three fixation methods for femoral neck fracture in young adults: experimental and numerical investigations. J Med Biol Eng. 2015; 35(5): 566-579.

8 Roerdink WH, Aalsma AM, Nijenbanning G,van Walsum AD. The dynamic locking blade plate, a new implant for intracapsular hip fractures: biomechanical comparison with the sliding hip screw and Twin Hook. Injury 2009; 40(3): 283-287

9. van Embden D, Stollenwerck GA, Koster LA, Kaptein BL,Nelissen RG, Schipper IB. The stability of fixation of proximal femoral fractures: a radiostereometric analysis. Bone Joint J. 2015 Mar;97-B(3):391-407. 10 Di Muria GV, Marcucci M, Pitto RP, Troiani M. Verified causes of failure in the treatment of femoral neck fractures with multiple Knowles pins. Ital J Orthop Traumatol 1991;17:107-116.

11 Husby T, Alho A, Nordsletten L, Bugge W. Early loss of fixation of femoral neck fractures: comparison of three devices in 244 cases. Acta Orthop Scand 1989;60:69-72.

12 Arnold WD. The effect of early weight-bearing on the stability of femoral neck fractures treated with Knowles pins. J Bone Joint Surg Am 1984;66:847-852.

13 Dewei Z, Xiaobing Y. A retrospective analysis of the use of cannulated compression screws and a vascularised iliac bone graft in the treatment of displaced fracture of the femoral neck in patients aged $<50$ years. 
Bone Joint J. 2014 Aug;96-B(8):1024-1028.

14 Slobogean GP1, Sprague SA2, Scott T3, Bhandari M2. Complications following young femoral neck fractures .Injury. 2015 Mar;46(3):484-491. 15 Li G, Jin D, Shao X, Liu Z, Duan J, Akileh R, Cao S, Liu T. Effect of cannulated screws with deep circumflex iliac artery-bone grafting in the treatment of femoral neck fracture in young adults. Injury. 2018 Aug;49(8):1587-1593

16 Wang Z,Yin Y, Li Q, Sun G, Peng X, Yin H, Ye Y. Comparison of early complications between the use of a cannulated screw locking plate and multiple cancellous screws in the treatment of displaced intracapsular hip fractures in young adults: a randomized controlled clinical trial. J Orthop Surg Res. (2018)13(1), 201.

17Loizou CL, Parker MJ.Avascular necrosis after internal fixation of intracapsular hip fractures; a study of the outcome for 1023 patients.Injury.2009,40(11):1143-1146.

18 Lenich A, Bachmeier S, PrantI L,Nerlich M, Hammer J, Mayr E, AL-Munajjed AA, Füchtmeier B. Is the rotation of the femoral head a potential initiation for cutting out? A theoretical and experimental approach. BMC Musculoskelet Disord 2011;12:79.

19 Wu CC. Using biomechanics to improve the surgical technique for internal fixation of intracapsular femoral neck fractures. Chang Gung Med J 2010;33:241-251. 
20 SMITH FB.Effects of rotatory and valgus malpositions on blood supply to the femoral head; observations at arthroplasty. J Bone Joint Surg Am. 1959 Jul;41-A(5):800-815.

21 Ly TV, Swiontkowski MF. Management of femoral neck fracture in young adult.Indian J Orthop. 2008,42:3-12..

22 Swiontkowski MF. Intracapsular fractures of the hip. J Bone Joint Surg Am 1994,76:129-138.

23 Parker MJ, Pryor GA, Myles JW. The value of a special surgical team in preventing complications in the treatment of hip fractures. Int Orthop. 1994;18:184-188.

24 Rogers FB, Shackford SR, Keller MS. Early fixation reduces morbidity and mortality in elderly patients with hip fractures from low-impact falls. J Trauma. 1995;39:261-265.

25 Zuckerman JD, Skovron ML, Koval KJ, Aharonoff G, Frankel VH. Postoperative complications and mortality associated with operative delay in older patients who have a fracture of the hip. J Bone Joint Surg Am. 1995;77:1551-1556. 
Figures

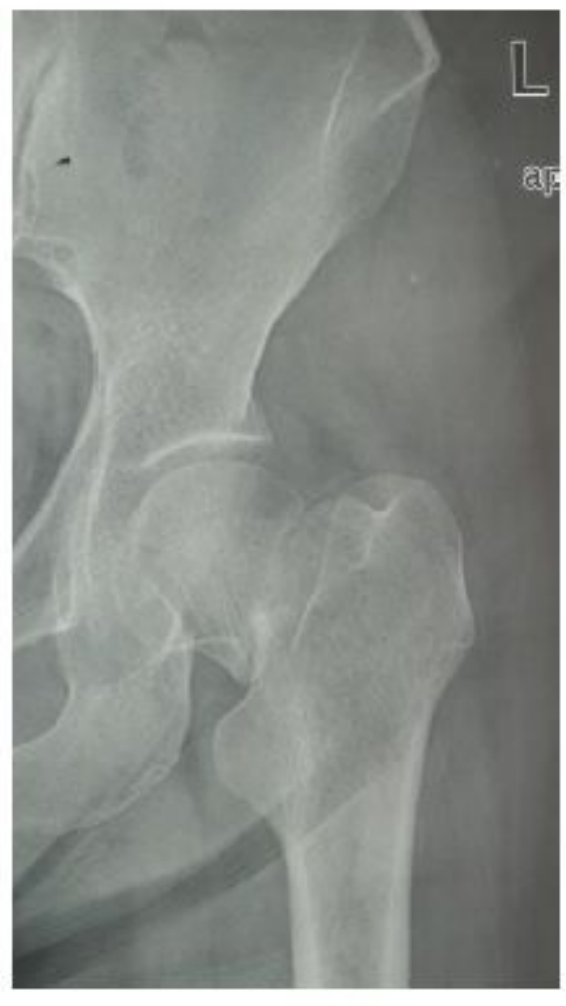

Fig. 1a

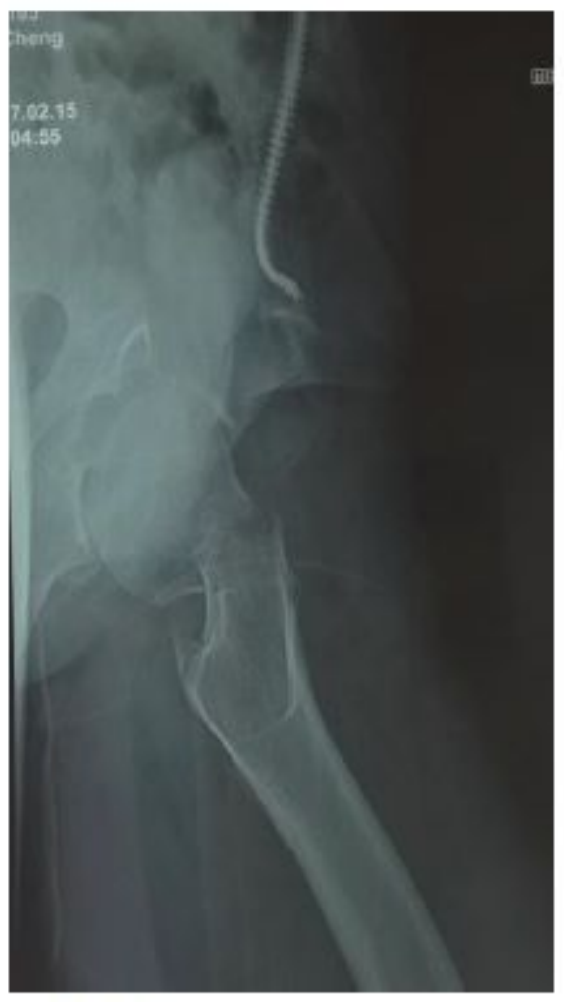

Fig. 1b

Figure 1

a) Anteroposterior and b) lateral radiograph of displaced femoral neck fracture in a 28-year-old man
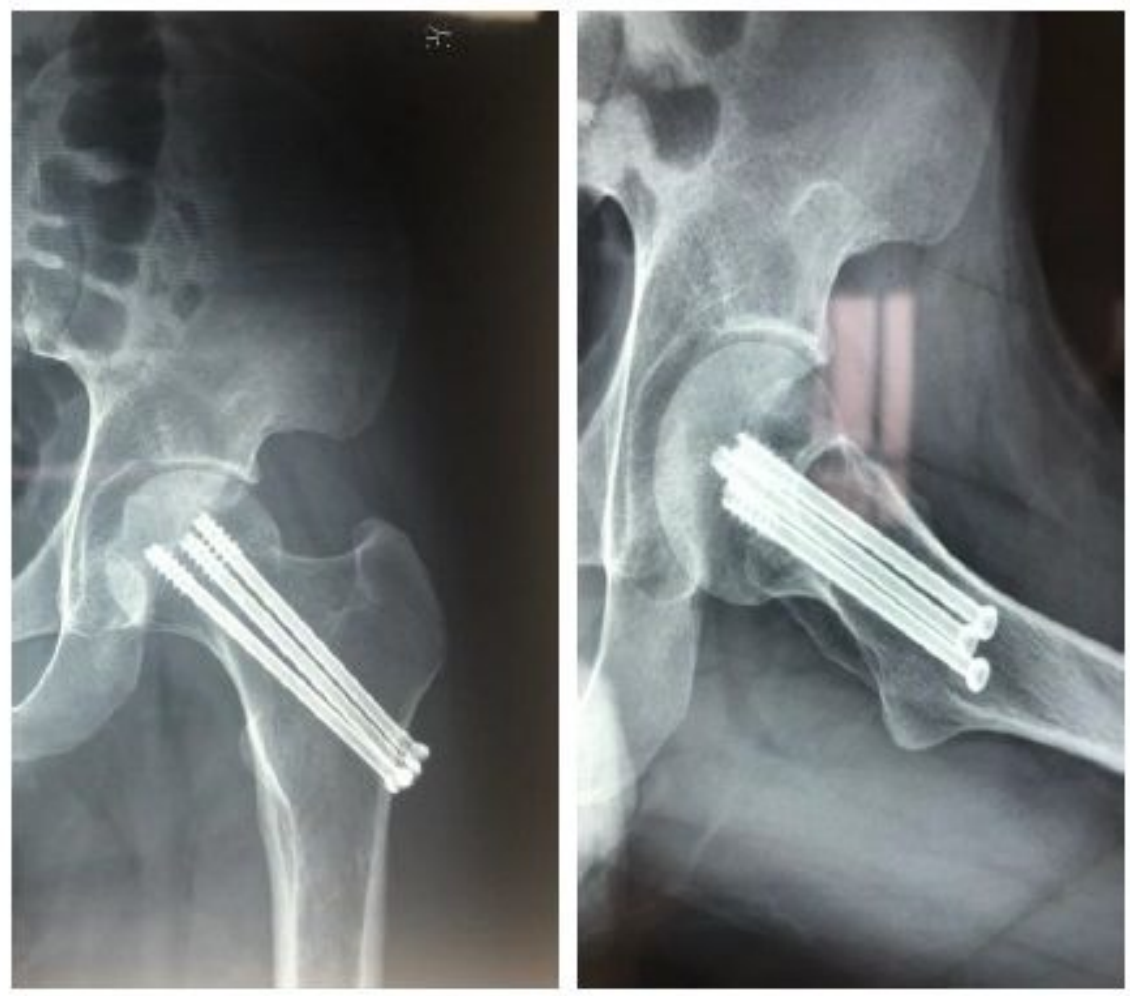

Fig. $2 a$

Fig. $2 b$ 


\section{Figure 2}

a) Anteroposterior and b) lateral radiograph of the patient in figure 1 fixed with cannulated screw with union of the fracture line.

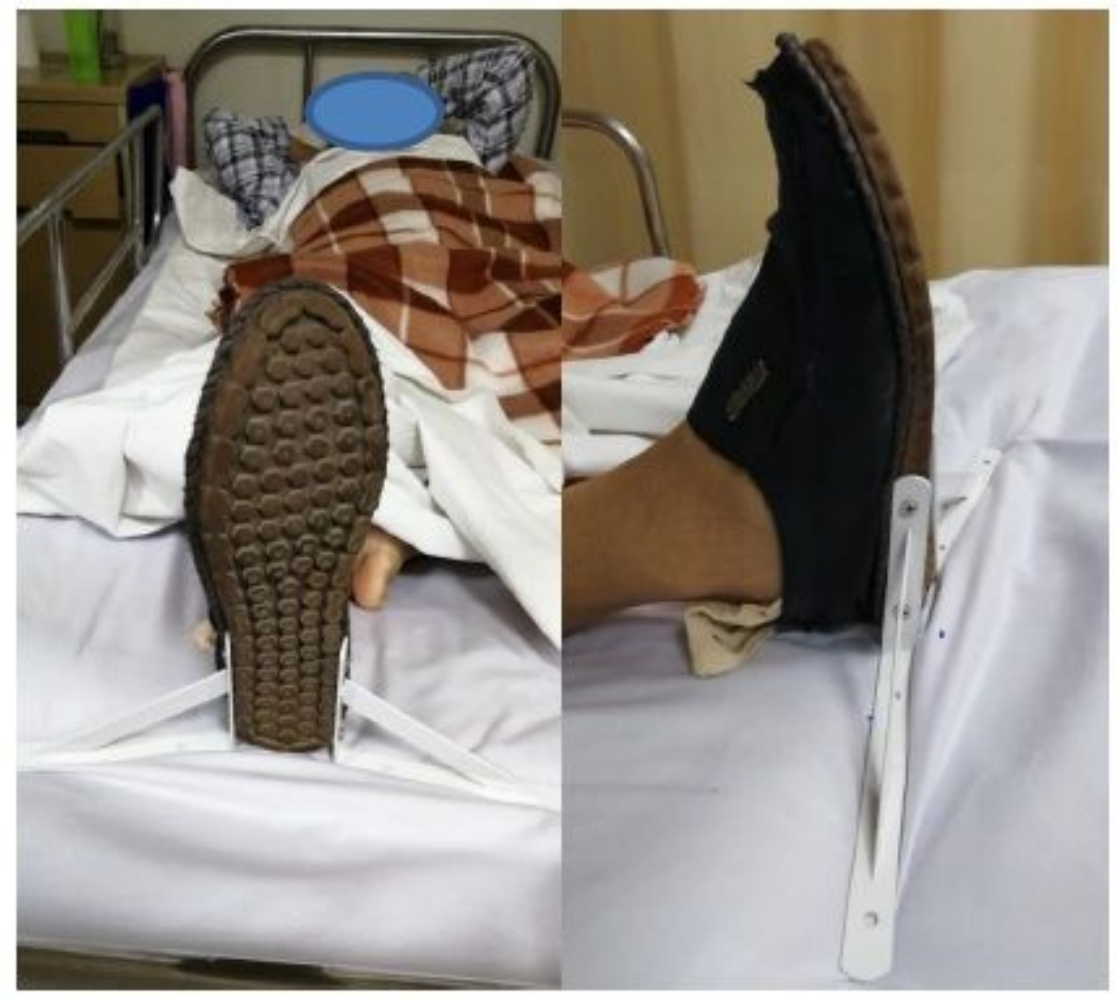

Fig. $3 a$

Fig. 3b

Figure 3

a) anterior view and b) lateral view : Postoperatively patients wore anti-rotation shoes (Nail a tripod on both sides of the heel) to control rotation at the fracture site to promote bone union and avoid osteonecrosis

\section{Supplementary Files}

This is a list of supplementary files associated with this preprint. Click to download.

- Table1.pdf 